\title{
PROPOSTA DE MELHORIA NO LAYOUT DE PRODUÇÃO UTILIZANDO A
}

\author{
FERRAMENTA SLP: um estudo de caso em uma indústria de implementos agrícolas
}

\section{PROPOSAL FOR IMPROVEMENT IN THE PRODUCTION LAYOUT USING THE SLP TOOL: a case study in an agricultural implementation industry}

Vagner Marcondes Corrêa - vagner.marcondes.matao36@gmail.com
Carlos Rodrigo Volante - carlos.volante@ fatectq.edu.br Faculdade de Tecnologia de Taquaritinga (FATEC) -SP -Brasil

DOI: 10.31510/infa.v16i2.631

\begin{abstract}
RESUMO
Com o mercado globalizado, as empresas buscam cada vez mais competitividade, por meio do planejamento da produção, este artigo apresenta um estudo de caso sobre arranjo físico em uma indústria que fabrica peças para implementos agrícolas, localizada em Matão, após observa-se o processo produtivo, maquinário, equipamentos, percebe-se uma deficiência no planejamento do layout, a partir desse contexto apoiado pela ferramenta SLP (Planejamento Sistemático do Arranjo Físico), pretende-se propor um novo, que seja possível agrupar as tarefas de acordo com a relação de prioridade, reduzindo deslocamento desnecessário de material entre os departamentos. O método utilizado para realização do trabalho foi um estudo de caso e revisão de monografias, artigos científicos e sites a fim de obter auxílio e entendimento sobre o assunto descrito. Os resultados da pesquisa proporcionam maior flexibilidade, busca estruturar conhecimentos e ferramentas disponíveis para o planejamento de arranjos físicos com maior eficiência, determinando assim a elaboração com melhorias.
\end{abstract}

Palavras-chave: Arranjo físico. Indústria. Layout. SLP.

\begin{abstract}
With the globalized market, companies are increasingly seeking competitiveness through production planning, this article presents a case study on physical arrangement in an industry that manufactures parts for agricultural implements, located in Matão, after observing the process production, machinery, equipment, it is perceived a deficiency in layout planning, from this context supported by the SLP (Systematic Planning of Physical Arrangement) tool, it is intended to propose a new one, which is possible to group the tasks according to the relationship priority, reducing unnecessary material displacement between departments. The method used to perform the work was a case study and review of monographs, scientific articles and websites in order to get help and understanding on the subject described. The research results provide greater flexibility, seek to structure knowledge and tools available for the planning of physical arrangements with greater efficiency, thus determining the elaboration with improvements.
\end{abstract}

Keywords: Physical Arrangement. Industry. Layout. SLP. 


\title{
1 INTRODUÇÃO
}

O cenário industrial brasileiro vem se transformando devido ao aumento da produtividade e busca de excelência na qualidade, dessa forma decidir sobre um layout é importante, pois, de modo geral exerce impacto direto nos custos da produção. Uma pequena mudança no arranjo pode provocar efeitos sobre produtividade, velocidade, segurança e ainda aperfeiçoar a eficácia. (CHIAVENATO, 1976). Com favorecimento na escoação da produção, espaço para crescer e incentivo técnico científico o interior paulista atraiu empresas da capital e de outros estados.

\begin{abstract}
A indústria de transformação representa $11 \%$ do PIB brasileiro, $36 \%$ das exportações e $63 \%$ dos gastos em pesquisa e desenvolvimento do setor privado e a cada $\mathrm{R} \$ 1,00$ produzido na indústria de transformação são gerados $\mathrm{R} \$ 2,63$ na economia brasileira. O estado de São Paulo é responsável por 32,1\% do PIB industrial nacional, empregando mais de 2.800 .000 trabalhadores correspondendo por $15 \%$ do emprego formal. Segundo (PORTAL DA INDÚSTRIA, 2019).
\end{abstract}

As dificuldades envolvidas com o layout são complexas, já que envolvem muitos fatores e conjuntos de variáveis. Conforme SEBRAE (2019) o tempo desperdiçado com a movimentação de matéria e produtos dentro da organização corresponde á 30\% do tempo de produção. Além de perdas por excesso de operações e ineficiência produtiva, aumentando necessidade de técnicas novas de planejamento da produção.

Com o incentivo empresarial de Getúlio Vargas presidente da época, em 1934 no Brasil observou-se conquistas significativas como: jornada de trabalho de oito horas diárias, direitos e incentivos para construção e implantação de empresa, aconteceu o que Chiavenato (1976) propôs, “o nascimento da escola clássica remontava-se as consequências geradas pela revolução industrial onde, no início do século XX ocorreu o crescimento acelerado e desorganizado das empresas".

\subsection{Problema da pesquisa}

Slack et al. (2002) é difícil executar mudança no arranjo físico de uma empresa e consequentemente pode gerar altos custos. Por isso é necessário analisar e entender os objetivos que deseja atingir com o novo layout. Por esse fator muitas empresas de médio e pequeno porte não conseguem adequar-se, muitas vezes por falta de capacitação ou até 


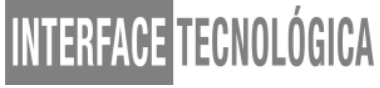

mesmo uma questão financeira, à elaboração inadequada pode causar efeitos graves, acarretando maior desperdício de tempo e recursos financeiros sem retorno.

A ênfase das empresas deve estar focada nas tarefas e na estrutura da organização, e a sua preocupação primordial era o aumento da eficiência da empresa por meio da forma e disposições dos órgãos departamentais e inter-relações estruturais, propondo a eliminação dos movimentos desnecessários, gerando maior eficiência da produção. (TAYLOR, 1989).

Já Chiavenato (1976), propôs, que o layout por processo é flexível para atender as mudanças do mercado, atendendo a diversidade de produtos, onde os equipamentos e/ou funções são agrupados juntos.

O trabalho será feito em uma empresa de médio porte no segmento metalúrgico de implementos agrícola com propósito de melhorar o layout que tem por característica apresentar longos roteiros de produção e grande movimentação de materiais utilizando o método SLP delimitam-se na sua aplicação, analisando a viabilidade e capacidade de implantação, além de verificar os benefícios em curto, médio e longo prazo.

Segundo Muther (1978), SLP (Planejamento Sistemático do Arranjo Físico), tem por finalidade identificar, avaliar e visualizar os elementos e as áreas instaladas envolvidas no conjunto, o planejamento é utilizando para compreender os fluxos de materiais, pessoas e produtos e suas inter-relações. Com tudo o SLP é considerado como uma ferramenta por Muther, já outros autores o consideram como metodologia, método e/ou sistema.

\subsection{Objetivo}

O objetivo do estudo é apresentar a Faculdade de Tecnologia de Taquaritinga, uma proposta de melhoria para o layout de uma indústria de implementos agrícolas utilizando o método SLP.

Sendo utilizada a ferramenta para estruturar os conhecimentos e técnicas disponíveis, auxiliando na tomada de decisão sobre o layout, o melhor posicionamento dos inputs e ferramentas na linha de produção, apresenta também uma ampla aplicabilidade nos sistemas produtivos atuais e serve de referência para instalações produtivas. (MUTHER 1978). 


\subsection{Justificativa}

A organização estudada vem competindo e crescendo fortemente no seu ramo de atuação, mudanças por fatores internos e externos verifica-se a necessidade de investimento em melhoria de desempenho, planejamento e adequação, já que muitos setores possuem grandes problemas, quais se referindo à distribuição de máquinas, ferramentas e fluxos de materiais confusos e sobrepostos.

Para manter a produtividade de peças para implementos agrícolas ao processo final de produção e por consequência atender à demanda solicitada pelos clientes com respeito a prazos e qualidade.

Então, será utilizado o método SLP, para solucionar os problemas, com a proposta de aperfeiçoar a produtividade e minimizar a movimentação, diminuindo perdas e aumentando desempenho da empresa no mercado.

\section{O MÉTODO SLP}

Para Muther (1978) são necessárias quatro fases para elaboração do SLP, composto por: localização, arranjo físico geral, arranjo físico detalhado e por último a implantação e rearranjo dos setores, o sistema deve seguir passo a passo os seguintes procedimentos propondo assim as mudanças.

Tabela 1: Fases da elaboração do SLP.

\begin{tabular}{c|l}
\hline Fase I: Localizar a área & $\begin{array}{l}\text { Planejar o local onde o novo arranjo será } \\
\text { implantado e/ou necessário utilizar um novo } \\
\text { espaço ou prédio. }\end{array}$ \\
\hline Fase II: Arranjo físico geral & $\begin{array}{l}\text { Definir a posição relativa das áreas em conjunto } \\
\text { com os modelos de fluxos e materiais. }\end{array}$ \\
\hline Fase III: Arranjo físico detalhado & $\begin{array}{l}\text { Especificar a localização de cada máquina e } \\
\text { equipamento, as características físicas, incluindo } \\
\text { serviços e insumos. }\end{array}$ \\
\hline Fase IV: Implantação e Rearranjo dos setores & $\begin{array}{l}\text { Ultima fase, na qual se executa o que foi planejado } \\
\text { edecide-se o arranjo trará beneficios e atenderá as } \\
\text { expectativas. }\end{array}$ \\
\hline
\end{tabular}

Fonte: Adaptado de Muther (1978).

Com isso a metodologia SLP é um mecanismo de apoio para tomada de decisão identificando as opções de um arranjo físico e descrevendo a que mais se adéquam as necessidades específicas e essências da empresa (SLACK ET. AL. 2002). 


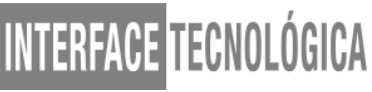

\section{METODOLOGIA}

A pesquisa bibliografia embasou no caso de estudo, com análise dos dados coletados. Para Marconi E Lakatos (2010), o conhecimento bibliográfico pode ser considerado e executado sobre a visão de qualitativo e quantitativo. Segundo Fernandes (2009), a pesquisa qualitativa é descritiva, os dados não podem ser traduzidos para números, sendo analisando com a observação, o raciocínio indutivo, já a quantitativa interpreta e traduz em números e depois classifica-los, o que pode ser calculado obtendo resultados confiáveis, por fim, os dados levantados serão utilizados para a implantação e proposta final do trabalho.

A pesquisa se dividiu em duas etapas, a primeira com ênfase na pesquisa exploratória e básica, levantamento do problema em questão, pesquisa em campo e estudo bibliográficos sobre arranjos físicos, análise de todo processo produtivo no layout atual dentro da empresa e o conceito do sistema SLP.

A etapa seguinte foi toda estruturada pelos passos da ferramenta SLP e suas aplicações, passeado na coleta de dados na primeira etapa, utilizando as ferramentas: diagramas, matrizes e cartas apresentados na mesma ferramenta aplicada, denotando um arranjo físico para atender as necessidades a ser avaliadas.

\section{ESTUDO DE CASO}

Conforme o estudo efetuado na empresa, devido á grande diversidade e locomoção de processos e produtos os materiais que a indústria de peças de implementos agrícolas oferece para o mercado, é importante adequar e manter o layout por processo em parque fabril. "Layout por processo é assim chamado, porque as necessidades e conveniências dos recursos transformadores que constituem o processo na operação dominam a decisão sobre a planta." (SLACK ET AL., 2002, p.203).

Para elaboração do projeto medições foram feitas em todos os departamentos da produção. Identificando problemas e gargalos no seu processo produtivo, decorrente do layout existente. Dentre eles estão: Fluxo de processos confusos e sobrepostos; setores não padronizados; segurança e dificuldade de controle e supervisão:

Com uma variedade de peças e materiais muito grande a movimentação dos processos fica confusa. Na figura 1, observa-se que os insumos percorrem grandes distâncias. 
Possuindo setores com espaços físicos maiores que os necessários para desenvolver o seu trabalho, como o caso da tornearia que possui um espaço maior que o necessário, onde muitas vezes é utilizado por setores vizinhos.

A solda e pintura podem ser consideradas setores críticos, por não possuírem boxes, os produtos químicos provenientes da pintura vão para a toda área da produção, na soldagem ocorre o mesmo, porém, é o gás, além da poeira da raspagem dos "respingos de solda".

A empresa por ser de médio porte os dois supervisores, um da usinagem que é responsável pelos setores: tornearia, serra, furadeira, fresadora. $\mathrm{O}$ outro pelos demais setores acabam tento dificuldade para supervisionar e controlar as atividades pelo distanciamento dos departamentos.

Situada na cidade de Matão, possuindo uma estrutura física compreendendo um barracão de $110 \mathrm{~m}$ de comprimento e $55 \mathrm{~m}$ de largura totalizando uma área de $5.075 \mathrm{~m}^{2}$ destinada à produção com tornos $\mathrm{CNC}$ e convencional, Fresadoras, estoque de produto e matéria-prima, serras, furadeiras, solda, pintura e corte a laser, produzindo por encomenda e estocando de segundo a necessidade do cliente. Na Figura 1 observa-se a planta do ambiente estudado com seu atual layout e seu fluxo de materiais, na Tabela 2 apresenta os departamentos com sua área e necessidades específicas para desenvolver seu trabalho.

Figura 1: Planta baixa da empresa e fluxo de materiais.

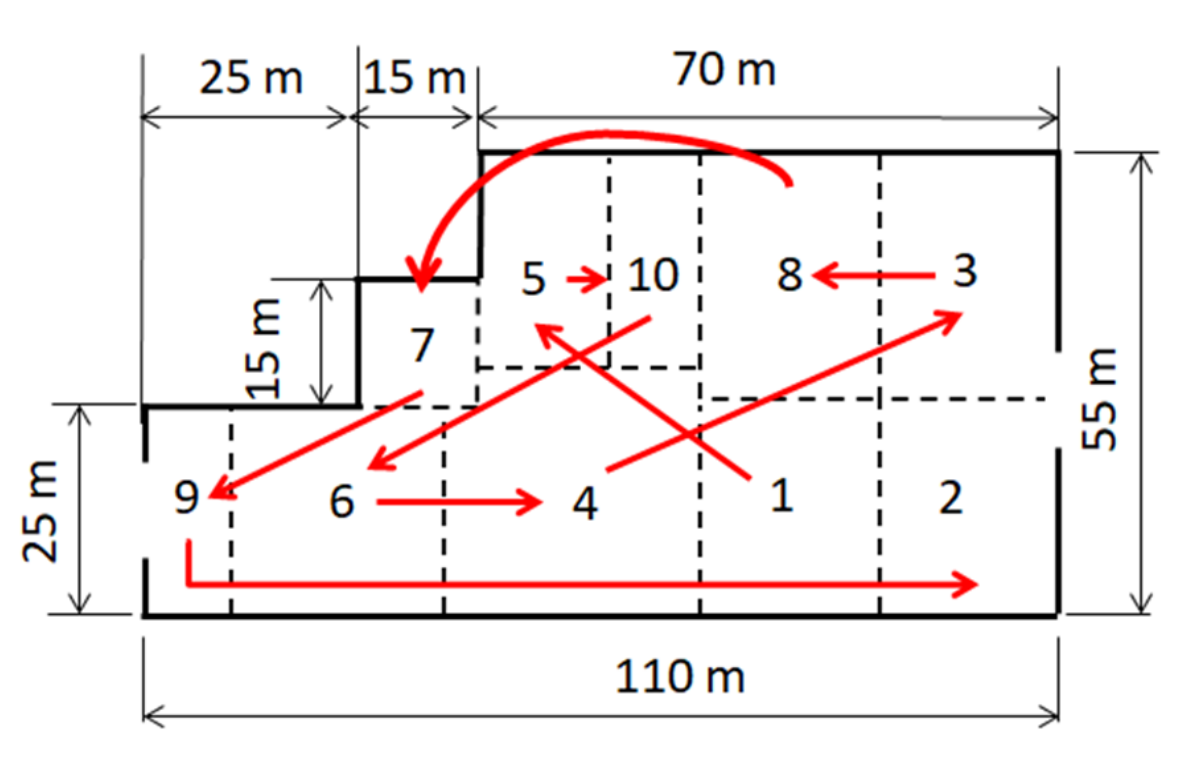

Fonte: Os Autores (2019).

Tabela 2: Áreas e características dos setores/atividades.

\begin{tabular}{l|l|l|l|l|l}
\hline \multicolumn{3}{|c|}{} & \multicolumn{3}{c}{ Necessidade específica } \\
\hline Número & Atividade/Setor & Área $\left(\mathbf{m}^{\mathbf{2}}\right)$ & Ar comprimido & Exaustor & Box \\
\hline
\end{tabular}






\begin{tabular}{c|l|c|c|c|c}
\hline 1 & Estoque matéria-prima & $500 \mathrm{~m}^{2}$ & & & \\
\hline 2 & Estoque produto pronto & $500 \mathrm{~m}^{2}$ & & & \\
\hline 3 & Fresadora & $600 \mathrm{~m}^{2}$ & $\mathrm{X}$ & & \\
\hline 4 & Furadeira & $900 \mathrm{~m}^{2}$ & $\mathrm{X}$ & & \\
\hline 5 & Serra & $500 \mathrm{~m}^{2}$ & & & \\
\hline 6 & Tornearia & $625 \mathrm{~m}^{2}$ & $\mathrm{X}$ & & \\
\hline 7 & Pintura & $225 \mathrm{~m}^{2}$ & $\mathrm{X}$ & $\mathrm{X}$ & $\mathrm{X}$ \\
\hline 8 & Solda & $600 \mathrm{~m}^{2}$ & & $\mathrm{X}$ & $\mathrm{X}$ \\
\hline 9 & Montagem & $375 \mathrm{~m}^{2}$ & $\mathrm{X}$ & & \\
\hline 10 & Corte Plasma & $250 \mathrm{~m}^{2}$ & $\mathrm{X}$ & & \\
\hline
\end{tabular}

Fonte: Os Autores (2019).

\subsection{Aplicação do SLP.}

A metodologia SLP é composta por passos, apoiados por ferramentas como: fluxograma, matriz ou carta de fluxo e atividades e diagrama de relação de espaço e finalmente se tem a escolha do layout, presentes na Tabela 3, ou seja, para Muther (1978), qualquer arranjo físico envolve: relação entre produto e quantidade, quanto de cada item deve ser produzido e como produzir da melhor forma, que se devido ao fato dos setores das empresas serem organizadas pela quantidade de cada produto.

Tabela 3: Passos do SLP.

\section{Passos}

Possiveis ferramentas

1. Análise de fluxos de produtos ou recursos Diagrama de fluxo ou diagrama de - para

2. Identificação e inclusão de fatores qualitativos Diagrama de relacionamento de atividades

3. Avaliação dos dados e arranjo de áreas de trabalho Diagrama de arranjo de atividades

4. Determinação de um plano de arranjo dos espaços Diagrama de relações de espaço

5. Ajuste do arranjo no espaço disponível Planta do local e modelos (templates)

Fonte: Adaptado de Corrêa e Corrêa (2012).

Apoiado na interpretação e análise por meio das ferramentas que constituem o sistema SLP apresenta por Muther (1978) cujo desenvolvimento é feito pela resolução dos seus passos, foi elaborado o fluxo do material dentro processo Figura 1, 


\subsubsection{Matriz das atividades e carta de fluxo.}

A importância das atividades e setores é indicada por meio da matriz de relação das atividades e fluxo, conforme a Figura 2. Assim é preciso relaciona as atividades, área, características e importância das instalações, pelo grau de proximidade.

Segundo Muther (1978), permite-se julgar a formar de base do arranjo físico, com base em critérios, tais como: grau de conveniência, proximidade e distância dos departamentos, usando letras com relação à proximidade dos setores. Como a letra A Proximidade absoluta; E - Especialmente importante; I - Importante; O - Proximidade Normal; U - Indiferente e X - indesejável.

Sugere-se a Matriz De-Para, que apresenta os fluxos existentes entre os setores com a quantidade de material de cada processo. Evidenciando a necessidade da organização com relação ao layout.

Figura 2: Matriz de relação das atividades e De - para.



Fonte: Os Autores (2019).

\subsubsection{Diagrama de relação de espaço}

A partir da Figura 2 e determinação das características dos espaços Tabela 2, foi desenvolvido o diagrama de relação de espaço, melhorando a visualização espaços do arranjo físico. Definido por Muther (1978) como um passo importante, pois nele é identificada a 


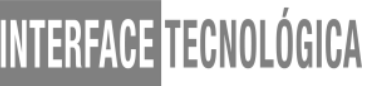

forma visual do espaço necessário para desenvolver cada atividade, podendo se fazer qualquer ajuste indispensável para completar as modificações.

Figura 3: Diagrama de relação de espaço.

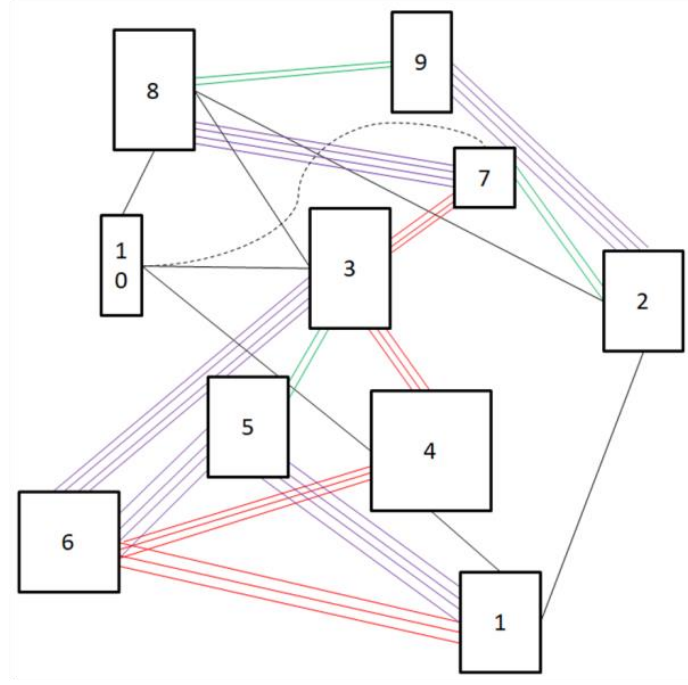

\begin{tabular}{|c|c|}
\hline Legenda & $\begin{array}{c}\text { Grau de } \\
\text { Proximidade }\end{array}$ \\
\hline 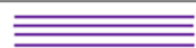 & A \\
\hline $\bar{\equiv}$ & E \\
\hline$\overline{\overline{ }}$ & I \\
\hline & $\mathrm{O}$ \\
\hline n, & $\mathrm{X}$ \\
\hline
\end{tabular}

Fonte: Os Autores (2019).

\section{ANÁLISE E DISCUSSÕES}

Conforme as etapas apresentadas por Muther (1978). Foi desenvolvido um layout que atenda os objetivos da empresa, considerando características de espaço e necessidade apresentadas na Figura 1 na planta baixa ajustando os espaços dos departamentos e atividades. O layout proposto é apresentado na Figura 4.

Figura 4: Arranjo físico proposto 1 e 2.

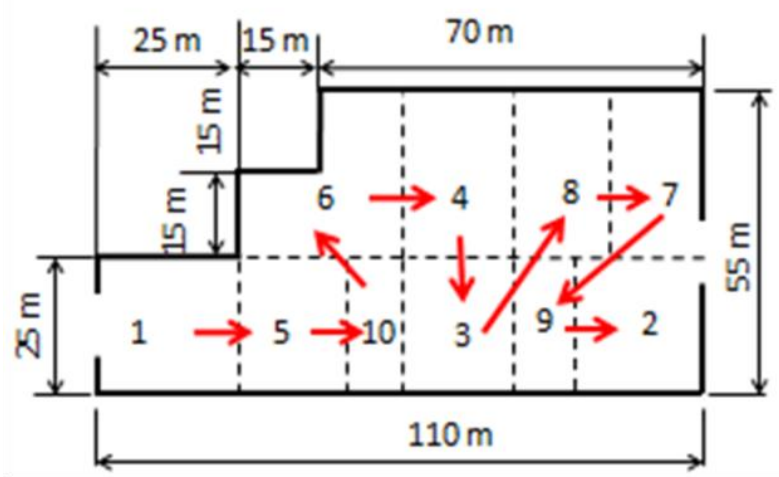






Fonte: Os Autores (2019).

A proximidade atual dos setores do corte plasma e soldagem podem ser perigosas, pois, o corte plasma utiliza gazes como a solda, mas com gases diferentes que podem causar danos ao patrimônio e ao pessoal e por não ser sequência próxima de produção, o distanciamento dos mesmos foram necessários.

Os setores da pintura e solda não possuem boxes de divisória, a pintura é feita em céu aberto no arranjo atual, perto da tornearia a prejudicando com o odor desagradável, como nos demais departamentos, assim no layout proposto foram feitos boxes de pintura com exautores proporcionando condições melhores de trabalho.

Um dos maiores problemas da empresa estava nos setores da tornearia e fresadora visto que se encontravam muitos distantes, por ser continuação da produção e passando-se o maior fluxo de produtos passando pelos mesmos. Além disso, as ferramentas e equipamentos são parecidos causam movimentação desnecessária.

Com isso a sequência da produção foi adequada conforme a maioria dos produtos, seguindo o maior fluxo, já que a empresa produz uma grande variedade de produtos.

\subsection{Considerando o layout proposto}

Observando os modelos de arranjo físicos propostos e com a nova disposição de setores foi possível adequar-se a um fluxo de produção contínuo e sem atividades sobrepostas e confusas, graças à proximidade que os setores se encontram.

Com as modificações presentes na Figura 5 tornou-se a melhoria concreta, reduzindo movimentação dada anteriormente pela distância de processos que é o principal problema e adequaram-se as características de um layout por processo que é o enfoque.

Como pode se perceber na Tabela 4 relacionando as distâncias que as matérias percorrem dentro da empresa no layout atual e no proposto. 


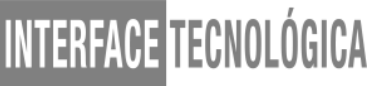

Tabela 4: Distância percorrida.

\begin{tabular}{c|c}
\hline & Distância percorrida estimada \\
\hline Atual & $405 \mathrm{~m}$ \\
\hline Layout 1 & $220 \mathrm{~m}$ \\
\hline Layout 2 & $180 \mathrm{~m}$ \\
\hline
\end{tabular}

Fonte: Os Autores (2019).

Observa-se eficácia de no mínimo 225 m comparando o arranjo atual e o proposto com a maior distância dos departamentos, tornando a medida de realocação e reestruturação necessária, ganhando tempo e reduzindo gastos com movimentação.

Os custos com mudança serão: com divisórias somente nos setores da solda e pintura com boxes, bem como os mesmos são necessários e considerados como EPC (equipamentos de proteção coletiva) garantindo a segurança, integridade dos colaboradores e do meio ambiente, os setores continuaram com apenas faixas de segurança, sem necessidade de mudança de estrutura com divisórias, além de deixar o fluxo da empresa mais limpo e de fácil compreensão.

Por fim, a empresa utiliza o ar comprimido em quase todos os seus processos, a estrutura já esta presente de modo que serão necessárias apenas adaptações, manutenções e revisões, fazendo que a ampliação, seja feita de um modo mais rápido e ágil, atendendo todas as expectativas do estudo.

\section{CONCLUSÃO}

Um novo layout é desafiador por demandar tempo e pessoal qualificado para se desenvolver, possuindo restrições com espaços e investimentos sua estruturação deve ser imparcial e objetiva, onde erros podem gerar atrasos da produção, custos não planejados, entre outros.

Neste contexto o layout possui um papel importante nos custos da produção, produto e eficiência operacional, sendo assim bem-planejado e executado aumenta a eficiência e produtividade da empresa, com resultados melhores na competitividade e prolongando sua atuação no mercado e vida útil.

Foi possível perceber a necessidade da organização em implantar um arranjo físico coerente com a produção, aplicando as estratégias do SLP, organizando o espaço e ordenando 


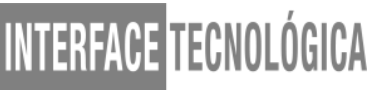

os recursos disponíveis da empresa, envolvendo pessoas que trabalham na empresa, fator de suma importância, assim tornado os resultados positivos, minimizando movimentações.

Além disso, devem-se utilizar técnicas metodológicas de apoio à decisão e cada alteração nos processos, produtos novos e fluxo são significativos e demandam novas configurações de layout, sugerindo a continuação da pesquisa.

\section{REFERÊNCIAS}

CHIAVENATO, Idalberto. Introdução à Teoria Geral Da Administração: uma visão abrangente da moderna administração das organizações / Idalberto Chiavenato - 7. Ed. Ver. E atual - Rio de Janeiro: Elsevier, 2003 - 12.

CORRÊA, Henrique L.; CORRÊA, Carlos A. Administração de produção e operações. 3. Ed. São Paulo: Atlas, 2012.

FAYOL, Henri, 1841-1925. Administração industrial e geral: previsão, organização, comando, coordenação, controle / Henri Fayol; [tradução para português de Irene de Bojano e Mário de Souza]. - 10. Ed. - São Paulo; Atlas, 1989.

FERNANDES, José Carlos de F. Administração de material um enfoque sistêmico. 2. Ed. Porto Alegre: Atlas, 2009.

GRAEMI, Jurandir Rets; GRAEMI, Alexandre Rets. Administração da produção: Operações industriais e de serviços. Curitiba: Unicenp, 2007.

INDÚSTRIA, Da Portal. A Importância da indústria no Brasil. Disponível em < http://www.portaldaindustria.com.br/estatisticas/importancia-da-industria/ >. Acesso em 15 jun 2019.

INDÚSTRIA, Da Portal. Participação Industrial: São Paulo. Disponível em < http://perfildaindustria.portaldaindustria.com.br/estado/sp >. Acesso em 15 jun 2019.

MARCONI, Maria de Andrade; LAKATOS, Eva Maria. Fundamento de Metodologia Cientifica. 7. Ed. São Paulo: Atlas, 2010.

MOREIRA, D. A. Administração da produção e operações. 2.ed. São Paulo: Cengage Learning, 2012.

MUTHER, R. Planejamento simplificado de Layout: Sistema SLP. 2. Ed. São Paulo: Edgard Blucher Ltda, 1978.

SEBRAE, O layout da fabrica pode influir na produtividade. Disponivel em < http://www.sebrae.com.br/sites/PortalSebrae/artigos/o-layout-da-fabrica-pode-influir-naprodutividade,83bc438af1c92410VgnVCM100000b272010aRCRD>.Acesso em 16 jun 2019.

SEVERINO, Antônio Joaquim. Metodologia do trabalho científico.2. Ed. São Paulo: Cortez, 2001. 
SLACK Nigel, CHAMBERS Stuart, HARLAND Christine, HARRISON Alan, JOHNSTON Robert (2002). Administração da produção. 3. Ed. São Paulo: Editora Atlas. 